\title{
Mortality of chrysotile asbestos workers at the Balangero Mine, Northern Italy
}

\author{
G. F. RUBINO ${ }^{1}$, G. PIOLATTO ${ }^{1}$, M. L. NEWHOUSE ${ }^{2}$, G. SCANSETTI ${ }^{1}$, \\ G. A. ARESINI ${ }^{3}, A N D R$. MURRAY ${ }^{4}$ \\ From the ${ }^{1}$ Istituto di Medicina del Lavoro, Turin, the ${ }^{2}$ London School of Hygiene and Tropical Medicine, \\ the ${ }^{3}$ Clinica del Lavoro, Milan, and ${ }^{4}$ Robert Murray Assosiates, London
}

\begin{abstract}
The mortality from 1946 to 1975 of over 900 North Italian chrysotile asbestos workers first employed between 1930 and 1965 has been studied. Nine deaths were certified as attributable to asbestosis, and eleven to lung cancer. One death was attributed to mesothelioma of pleura, but this diagnosis was not supported by histological examination. Comparison with the national figures for all Italy did not reveal an excess of deaths from lung cancer but during the last quinquennium of observation, the SMR for lung cancer rose to 206. Simulation experiments enabled a dust index in fibre/years to be attached to each man in the cohort. All but two of the deaths from lung cancer occurred in the higher exposure group. The relative risk of lung cancer in this group was $2 \cdot 89$. The eleven workers who died from lung cancer were all cigarette smokers. A further period of observation is required to monitor the mortality of the surviving workers.
\end{abstract}

The Balangero mine and mill of the Amiantifera Company is the only asbestos mine in Europe. It is located in the foothills of the Alps, about $30 \mathrm{~km}$ north-west of Turin. It started in 1916 and the production of pure chrysotile asbestos has increased year by year (with the exception of the war years from 1939 to 1945 ) so that now it produces 500 tons of asbestos per day from the crushing of 9000 tons of serpentine rock, derived by open cast mining (Figure).

The work force has numbered about 300 men. At present some 350 men are employed in the mine and its associated milling, crushing, screening and bagging plant.

In the early years and until after the war conditions were very dusty, the mining area being recognisable from some considerable distance by the pall of dust which hung over it. Since the war, with the introduction of modern techniques of primary crushing, transport, drying, separation and packing, the dust concentrations have been materially reduced.

The mining process currently consists of drilling the rock and inserting explosive charges. When these have been detonated the rock is scooped up by mechanical shovels into a primary crusher, under closed

Received for publication 22 May 1978

Accepted for publication 29 September 1978 circuit television control, and conveyed by an enclosed conveyor belt to a series of vertical static and horizontal rotating driers. Fibres are separated from the particles of rock by a pneumatic system under automatic control through a series of screens, the fibres being regularly sampled for quality before going to the packing department, while the rock waste is removed by conveyor belt to a tip one kilometre away. In the packing department the fibres are filled according to quality into paper or plastic sacks, compressed and put on to pallets for storage and ultimate transport. Efficient maintenance of the enclosure, mechanical handling and packing systems is essential for effective dust control.

The first investigation of the mortality of the Balangero workers was made by Ghezzi et al. (1972) on miners employed between 1932 and 1970. Comparison of mortality from lung cancer between the miners and the male inhabitants of two neighbouring villages gave no indication of a raised incidence of lung cancer among the miners. A proportional mortality study shows a close similarity between the Balangero miners and the miners of the Quebec province (McDonald, 1973).

This paper reports the results of a further study of the mortality of the Balangero miners, continued until 1975. A survey of the respiratory function and radiological status of current and ex-miners is also being undertaken. 


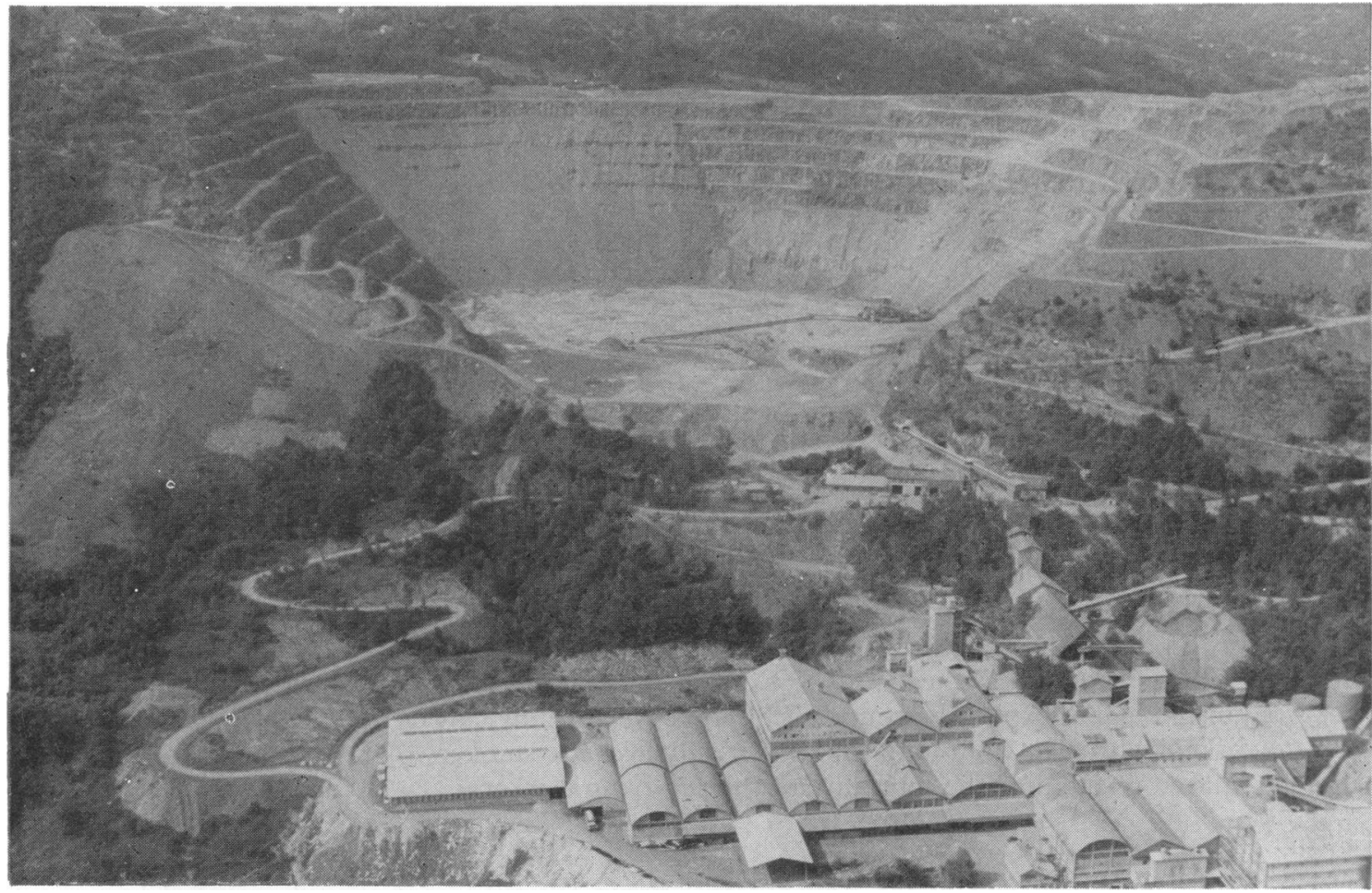

Figure Open cast asbestos mining at Balangero.

\section{Methods}

The records of the mining company provided a nominal roll of all those ever employed on the site. The population in the area is very stable, many men having retired to local villages. In Italy the death certificate is held at the Registrar's office at the individual's place of death, and we were able to obtain a copy. Further verification of vital status was obtained from registers of current residence.

The mine records provided the date of birth, the date of engagement at the mine, the date of termination of employment, job particulars, the date of death if known and the last known address.

The cohort consisted of 952 male workers with at least 30 calendar days' employment at any time between 1 January 1930 and 31 December 1965, but workers employed between 1930 and 1945, who did not survive to 1 January 1946, and where vital status could not be ascertained, were excluded. Mortality between that date and 31 December 1975 was examined. Workers not surviving till the post-war period were excluded, because wartime conditions altered mortality patterns and increased difficulties in follow-up. Thus among the 54 ex-miners dying before 1946, 26 died of violent causes, and a further 27 men were lost to follow-up during war. A small number of contract workers employed from time to time on the Balangero site were also excluded from the cohort.

\section{ASSESSMENT OF RISK}

Balangero miners and millers come from a mountainous region and an adequate standard population is not easy to identify. Because death rates for the region are not available, an approach using two different reference groups was used, following as far as possible methods suggested by McDonald and Liddell (1978).

In the first analysis the observed number of deaths was compared with the expected number in the population of all Italy. Person-years of observation were calculated according to the method of Case and Lea (1955) and multiplied by age-specific death rates to compute the expected number of deaths. As mortality data were recorded in Italy only since 1951, national rates for 1951 were used for the period 1946-51. Mortality data were collected until the end of 1975. The statistical analysis is therefore based on the 332 deaths occurring between 1946 and 1975 . The 
individual contribution to person-years of observation is given only from 1 January 1946 for those starting work in 1946 or before, and from the date of first employment for those who started work later. Five-year age groups and calendar years were used for the computation. Standardised mortality ratios were calculated and the Poisson distribution was used to test statistical significance. The cause of death was coded according to the 7th Revision of the International Classification of Diseases (World Health Organization, 1957).

Secondly, a case control study of carcinoma of lung and larynx as used by McDonald et al. (1974) and described by Liddell et al. (1977) was undertaken. Only two exposure categories were considered, the first with cumulative exposure up to 100 fibre-years and the second, all those with a cumulative exposure greater than 100 fibre/years. As the number of deaths from the two causes was very small, finer gradations of exposure would further reduce the reliability of comparison. The lower of the two exposure categories corresponds to the current British standard of 2 fibres/cc for 50 years' working life, at present the most generally accepted international standard.

For the case control study, five controls were selected at random for each case on the following criteria: each control was born within one year of the birth date of the case and was alive at the time of death of the relevant case. The total exposure accumulated by each control at the time of death of the relevant case was calculated, the relative risk was then computed and the $\chi^{2}$ test (Mantel and Haenszel, 1959) was used to judge significance. Age-adjusted incidence rates for cancer of the lung, larynx and gastrointestinal tract and for respiratory and cardiovascular diseases were then calculated for the two exposure categories, the lower being taken as an internal control. The direct standardisation method was used with the age structure of the whole cohort as standard. For the internal comparison we used the diagnosis from the most reliable source (Enterline, 1976). Thus we have twelve deaths from lung cancer in this group, whereas in the comparison with the national rates only the 11 deaths which were coded by the ICD rubrics $162 / 163$ from the cause of death on the death certificate were included. Two other deaths otherwise certified were transferred to the respiratory diseases group after we had examined hospital records.

\section{EXPOSURE DATA AND QUANTIFICATION}

Individual details of jobs while in employment were obtained from factory records and checked where possible by asking colleagues still at work. Jobs were classified as mining, crushing, waste dumping, screening and fibre separation, bagging and storage, and maintenance. Almost all workers had changed their job during their working life at the factory. An attempt has therefore been made to quantify individual exposure by calculating, for each worker, an approximate value for the accumulated dose of inhaled fibres.

Fibre counts at the plant were first carried out in 1969. In order to categorise jobs by dust exposure levels before 1969, conditions were created in the plant to reproduce working situations comparable to those occurring at various periods between 1946 and 1975. The factory archives were examined for information on daily production, the equipment used, the nature of the job and the number of hours worked per day. Four workers with continuous employment since 1935 helped to reconstruct the appropriate conditions, after which fibre counts were carried out by membrane filter collection and phase contrast microscopy $(\times 450)$.

The estimated values of past fibre concentration have considerable limitations: they are essentially mean values for each of the large job categories previously mentioned and include all workers in those jobs, although there were probably considerable individual variations in exposure. Furthermore, values obtained by reproducing standard conditions make no allowance for changes in the weather which may cause significant differences in the amount of dust in air.

On the basis of the available information, weighting factors were introduced to make the data comparable to current conditions. For example, many of the more dusty operations, such as drilling, had a duration of only 1-2 hours in a working day; on the other hand, working shifts were longer in the past (up to 48 hours per week until 1963). When corrections are made for work duration, the effect of peak concentrations is lost. Fibre levels expressed as the mean of various simulation experiments at different periods for four important jobs in the mine are shown in Table 1.

The dust index for each worker was calculated by adding the value of fibres/cc for each year in the specific job category. Individual exposure can then be expressed as fibre/years. In $\mathbf{3 8}$ workers for whom no details of job were available, the mean value of all jobs was assumed and the same applied to a few individuals engaged as maintenance workers. Six men, of whom four were dead, for whom there was no information on the date of last employment, were excluded from analyses concerned with exposure category.

\section{Results}

The follow-up of the cohort was satisfactory (Table 2) in that reliable evidence of vital status was ob- 
Table 1 Mean concentrations of asbestos fibres ( fibre/cc) at various periods in representative jobs

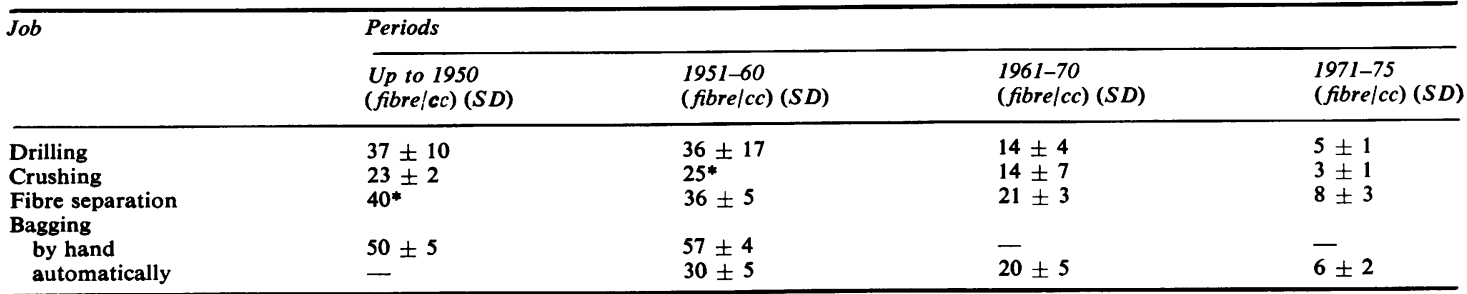

* Based on a single experiment because there was no change in methods during the period.

Table 2 Follow-up and vital status of the cohort

\begin{tabular}{lcc}
\hline Subjects & Number & Percentage \\
\hline Total in study & 952 & $100 \cdot 0$ \\
Traced & 933 & $98 \cdot 0$ \\
Lost to follow-up & 19 & $2 \cdot 0$ \\
Alive & 601 & $63 \cdot 1$ \\
Dead & 332 & $34 \cdot 9$ \\
\hline
\end{tabular}

tained for $98 \%$ of the subjects. Losses to follow-up occurred fairly uniformly over time of observation since 1946 and were caused mainly by migration. For simplicity the 19 workers lost to follow-up were excluded from the person-year count, reducing the total man-years of follow-up by 200 (less than $1 \%$ ). Approximately one-third of the cohort had died.

In Table 3 the mortality of the cohort is divided into two groups according to period since first employment: deaths occurring up to 19 years since first employment, and deaths occurring over 20 years since first employment. The overall mortality compared to the national figures is also given. Ten of the deaths from lung cancer occurred in the group with the longer latent period, but the expected number of deaths had increased correspondingly.

One death in 1975, certified as caused by pleural mesothelioma, occurred 35 years after starting employment in a worker with 33 years exposure. The diagnosis was based on cytological examination of pleural fluid, radiological findings and clinical examination to exclude primary cancer of other sites. No histological confirmation was available, so the diagnosis can be accepted only with reservations. Including this death there is little difference between the observed and expected deaths calculated on national figures for lung cancer (11 observed: 10.4 expected).

A significant excess of laryngeal cancer is seen when examining mortality over the whole period of observation. Four of these deaths occurred after 20

Table 3 Number of deaths observed and expected by period since first exposure, and cause.

(Period of observation from 1946 to 1975)

\begin{tabular}{|c|c|c|c|c|c|c|c|c|c|}
\hline Period since first exposure (yr) & Up to 19 & & & 20 and ove & & & Total & & \\
\hline Person-years observation & 12683 & & & 8776 & & & 21459 & & \\
\hline Cause of death & Observed & Expected & $S M R$ & Observed & Expected & $S M R$ & Observed & Expected & $S M R$ \\
\hline All causes & 112 & $54 \cdot 2$ & $207 * *$ & 220 & $160 \cdot 2$ & $137 * *$ & 332 & $214 \cdot 4$ & $155^{* *}$ \\
\hline $\begin{array}{l}\text { All malignant neoplasms (140-205) } \\
\text { Lung and pleura (162-163) } \\
\text { Larynx (161) } \\
\text { Gastrointestinal (151-159) } \\
\text { Other sites }\end{array}$ & $\begin{array}{r}12 \\
1 \\
2 \\
4 \\
5\end{array}$ & $\begin{array}{r}10.0 \\
1 \cdot 7 \\
0.4 \\
4 \cdot 8 \\
3 \cdot 1\end{array}$ & $\begin{array}{r}120 \\
59 \\
500 \\
83 \\
161\end{array}$ & $\begin{array}{c}38 \\
10 \dagger \\
4 \\
15 \\
9\end{array}$ & $\begin{array}{r}37 \cdot 0 \\
8 \cdot 7 \\
1 \cdot 5 \\
14 \cdot 5 \\
12 \cdot 3\end{array}$ & $\begin{array}{r}103 \\
115 \\
267 \\
103 \\
73\end{array}$ & $\begin{array}{c}50 \\
11 \dagger \\
6 \\
19 \\
14\end{array}$ & $\begin{array}{r}47 \cdot 0 \\
10 \cdot 4 \\
1 \cdot 9 \\
19 \cdot 3 \\
15 \cdot 4\end{array}$ & $\begin{array}{c}106 \\
106 \\
316^{*} \\
98 \\
91\end{array}$ \\
\hline $\begin{array}{l}\text { Non-malignant respiratory diseases }(470-527) \\
\text { Influenza and pneumonia }(480-493) \\
\text { Other respiratory diseases }(470-475,500-527) \\
\text { Asbestosis }(523 \cdot 2)\end{array}$ & $\begin{array}{r}12 \\
8 \\
4 \\
2\end{array}$ & $\begin{array}{l}2 \cdot 3 \\
1.6 \\
0 \cdot 7 \\
-\end{array}$ & $\begin{array}{l}522 * * \\
500 * * \\
571 * * \\
-\end{array}$ & $\begin{array}{r}20 \\
4 \\
16 \\
7\end{array}$ & $\begin{array}{r}11 \cdot 8 \\
4 \cdot 6 \\
7 \cdot 2 \\
-\end{array}$ & $\begin{array}{l}169 * \\
87 \\
222^{* *} \\
-\end{array}$ & $\begin{array}{r}32 \\
12 \\
20 \\
9\end{array}$ & $\begin{array}{r}14 \cdot 1 \\
6 \cdot 2 \\
7 \cdot 9 \\
-\end{array}$ & $\begin{array}{l}227^{* *} \\
194^{*} \\
253^{* *} \\
-\end{array}$ \\
\hline $\begin{array}{l}\text { Tuberculosis of the lung }(001-008) \\
\text { Cardiovascular diseases }(400-468) \\
\text { Cirrhosis of the liver (581) } \\
\text { Accidents (800-999) } \\
\text { All other causes } \\
\text { Unknown }\end{array}$ & $\begin{array}{r}13 \\
22 \\
9 \\
30 \\
9 \\
5\end{array}$ & $\begin{array}{r}3 \cdot 9 \\
14 \cdot 8 \\
2 \cdot 1 \\
7 \cdot 8 \\
13 \cdot 3 \\
-\end{array}$ & $\begin{array}{l}333 * * \\
149 \\
429 * * \\
385^{* *} \\
68 \\
-\end{array}$ & $\begin{array}{r}5 \\
100 \\
22 \\
15 \\
17 \\
3\end{array}$ & $\begin{array}{r}3 \cdot 3 \\
67 \cdot 7 \\
7 \cdot 8 \\
9 \cdot 5 \\
23 \cdot 1 \\
-\end{array}$ & $\begin{array}{l}152 \\
148 * * \\
282^{* *} \\
158 \\
74 \\
-\end{array}$ & $\begin{array}{r}18 \\
122 \\
31 \\
45 \\
26 \\
8\end{array}$ & $\begin{array}{r}7 \cdot 2 \\
82 \cdot 5 \\
9 \cdot 9 \\
17 \cdot 3 \\
36 \cdot 4 \\
-\end{array}$ & $\begin{array}{c}150^{* * *} \\
148^{* *} \\
313^{* *} \\
260^{* *} \\
71 \\
-\end{array}$ \\
\hline
\end{tabular}

${ }^{*} P<0.05 ; *^{*} P<0.01$.

These numbers include one suspected case of mesothelioma of the pleura.

Figures in parentheses are ICD (7th Revision) Code numbers. 
years since first employment. Two of the six workers dying of laryngeal cancer had less than one year of exposure. There is also a marked excess of respiratory diseases, both influenza and pneumonia and 'other respiratory diseases', consisting chiefly of chronic obstructive lung disease. Asbestosis was reported on nine death certificates as the leading cause of death and was certified as the underlying cause of death in two cases of lung cancer and one case of laryngeal cancer. Excess deaths from causes not related to asbestos exposure, such as accidents and cirrhosis of the liver, are also seen.

The mortality from lung cancer according to secular trend is examined in Table 4. No deaths were observed before 1961, nor did any deaths occur from this cause in subjects under the age of 50 . However, among those of 50 years and over, the SMR rises to 111 in the quinquennium 1966-70 and reaches 226 between 1971 and 1975; for men of all ages, it is 206 in the same period.

Table 5 shows the distribution of the deaths of men with lung cancer and their controls in the two exposure categories, in the upper part of the table, and the deaths from laryngeal cancer with their controls, in the lower half of the table. Ten of the deaths from lung cancer are in the higher exposure group with a relative risk of $2 \cdot 89$. However, tests of the significance of the association of lung cancer and high exposure gave a two-tailed $P$ value of $0 \cdot 18$, thus demonstrating no statistically significant difference between the proportion of cases and controls reaching the higher exposure level. Nor is there a statistically significant excess of laryngeal cancer in the higher exposure categories (relative risk 3.33, twotailed $P$ value $0 \cdot 28$ ), although all but one of the deaths occurred in this group.

An attempt was made to obtain smoking histories for lung and laryngeal cancer patients and their controls, through interviews conducted by a social worker with the relatives of deceased or with the survivors. Such information could be obtained about
Table 5 Distribution of patients with lung and laryngeal cancer and their matched controls according to cumulative dust exposure

\begin{tabular}{lll}
\hline Subjects & Dust exposure \\
\cline { 2 - 3 } & Up to 100 fibre $/ y r$ & 101 and over fibre/yr \\
\hline Lung cancer & 2 & $10 \dagger$ \\
Controls & 22 & 38 \\
Relative risk & 1 & $2 \cdot 89^{*}$ \\
Laryngeal cancer & 1 & 5 \\
Controls & 12 & 18 \\
Relative risk & 1 & $3 \cdot 33^{* *}$ \\
\hline
\end{tabular}

†ncluding one case of lung cancer diagnosed in hospital but reported in death certificate as 'cardiac failure' and one suspected case of mesothelioma of the pleura.

*two-tailed $P$ value 0.18 .

**two-tailed $P$ value 0.28 .

all the workers who died of lung cancer and of laryngeal cancer, for 54 of the controls for men with lung cancer and for 27 of the controls for men with laryngeal cancer. None of the 12 men who died from lung cancer were non-smokers, but among them there were two light smokers (1-5 per diem). All those dying from laryngeal cancer were smokers (Table 6).

Table 7 shows the distribution of the whole cohort according to the selected exposure categories. For this analysis, workers included in the higher exposure category contributed to person-years observation in the lower category 'up to 100 fibre/years' from the date of first employment to the date they reached the cumulative dust exposure of 'more than 100 fibre/ yr', after which they contributed to the higher category. The mean value of cumulative dust exposure in the higher category was about five times that in the lower (75 fibre/yr compared with 376 fibre/yr). About two-thirds of the cohort reached the higher exposure category. In Tables 7 and 8, man-years from 1 January 1946 only are included in the total. Thus, those who had accumulated a dose of 100

Table 4 Observed and expected deaths from lung cancer (162-163) by age and calendar time

\begin{tabular}{|c|c|c|c|c|c|c|}
\hline \multirow[t]{2}{*}{ Age } & \multicolumn{6}{|c|}{ Calendar years of follow-up } \\
\hline & & $1946-60$ & $1961-65$ & $1966-70$ & $1971-75$ & $1946-75$ \\
\hline Up to 49 & $\begin{array}{l}\text { Observed } \\
\text { Expected } \\
\text { SMR }\end{array}$ & $\begin{array}{l}0 \\
0.5 \\
-\end{array}$ & $\begin{array}{l}0 \\
0.2 \\
-\end{array}$ & $\begin{array}{l}\mathbf{0} \\
\mathbf{0 \cdot 3} \\
-\end{array}$ & $\begin{array}{l}0 \\
0.3 \\
-\end{array}$ & $\begin{array}{l}0 \\
1 \cdot 3 \\
-\end{array}$ \\
\hline 50 and over & $\begin{array}{l}\text { Observed } \\
\text { Expected } \\
\text { SMR }\end{array}$ & $\begin{array}{l}0 \\
1 \cdot 7 \\
-\end{array}$ & $\begin{array}{l}1 \\
63\end{array}$ & $\begin{array}{c}3 \\
2 \cdot 7 \\
111\end{array}$ & $\begin{array}{c}7 \dagger \\
3 \cdot 1 \\
226\end{array}$ & $\begin{array}{r}11 \dagger \\
9 \cdot 1 \\
121\end{array}$ \\
\hline All ages & $\begin{array}{l}\text { Observed } \\
\text { Expected } \\
\text { SMR }\end{array}$ & $\begin{array}{l}0 \\
2 \cdot 2 \\
-\end{array}$ & $\begin{array}{l}1 \\
56\end{array}$ & $\begin{array}{c}3 \\
3 \cdot 0 \\
100\end{array}$ & $\begin{array}{c}7 \dagger \\
3 \cdot 4 \\
206\end{array}$ & $\begin{array}{c}11 \dagger \\
10 \cdot 4 \\
106\end{array}$ \\
\hline
\end{tabular}

†These numbers include one suspected case of mesothelioma of the pleura. 
Table 6 Distribution of cases and controls by cumulative dust exposure and smoking habit

\begin{tabular}{lllll}
\hline $\begin{array}{l}\text { Diagnosis and } \\
\text { smoking habit }\end{array}$ & \multicolumn{2}{l}{ Dust exposure } & \\
\cline { 2 - 5 } & \multicolumn{2}{l}{ Up to 100 fibre/yr } & 101 and over fibre/yr \\
\hline Lung cancer & & & & \\
Non-smokers & Cases & 0 & Cases & 0 \\
& Controls & 6 & Controls & 7 \\
Smokers & Cases & 2 & Cases & 10 \\
& Controls & 13 & Controls & 28 \\
Unknown & Cases & 0 & Cases & 0 \\
& Controls & 3 & Controls & 3 \\
& & & & \\
Laryngeal cancer & Cases & 0 & Cases & 0 \\
Non-smokers & Controls & 2 & Controls & 5 \\
& Cases & 1 & Cases & 5 \\
Smokers & Controls & 8 & Controls & 12 \\
& Cases & 0 & Cases & 0 \\
Unknown & Controls & 2 & Controls & 1 \\
\hline
\end{tabular}

Table 7 Distribution of workers according to cumulative dust exposure. Period of observation from 1946 to 1975

\begin{tabular}{lccc}
\hline $\begin{array}{l}\text { Dust exposure } \\
\text { as fibre/yr }\end{array}$ & $\begin{array}{l}\text { Up to } \\
\text { 100 fibre/yr }\end{array}$ & $\begin{array}{l}\text { 101 and over } \\
\text { fibre/yr }\end{array}$ & Unknown \\
\hline $\begin{array}{l}\text { Mean value within } \\
\text { categories }\end{array}$ & $74 \cdot 7$ & $376 \cdot 2$ & - \\
$\begin{array}{l}\text { Number in study } \\
\text { Person-years observation }\end{array}$ & 8365 & 611 & $6 * *$ \\
\hline
\end{tabular}

*Including the 611 workers in the category ' 101 and over fibre/yr' before they had reached such cumulative exposure. Person-years are additive, whereas number of workers are not.

**Including 4 dead.

fibre/yr by 1946 , immediately entered the higher exposure category.

The age-standardised death rates and the associate measure of risk for overall mortality and some selected causes of death are shown in Table 8. The relative risk for lung cancer obtained by examining the whole cohort $(2 \cdot 54)$ is similar to that calculated for the case control study $(2 \cdot 89$, Table 5$)$. A higher death rate for laryngeal and gastrointestinal cancer is also seen in the more highly exposed group, although comparison with the national statistics showed no excess for gastrointestinal cancers. Nonmalignant respiratory diseases, including asbestosis, tuberculosis and cardiovascular diseases, showed an increase in relative risk, whereas death rates for all other causes were almost equal in the two exposure groups.

\section{Discussion}

Although this chrysotile mine has been in operation since 1916 , the total population whose mortality has been studied consists of only 952 men. The same population was studied by Ghezzi et al. (1972). In the present study, only the 332 deaths occurring between 1946 and 1975 have been analysed.

The total number of deaths exceeded the number to be expected in the general population by approximately $50 \%$. About $42 \%$ of the excess deaths were due to violent causes and cirrhosis of the liver, indicating factors among the miners not affecting the general population to the same extent. Comparatively few deaths could be directly attributed to asbestos exposure. There were nine deaths from asbestosis, and 11 from lung cancer, including one unconfirmed death from a pleural mesothelioma. The SMR for lung cancer for the whole period is 106 but in the last five years of the study between 1970-75 there is an excess mortality from lung cancer (7 observed; 3.4 expected) giving an SMR of 206.

There were insufficient data to examine the validity of the additive or multiplicative models for cigarette smoking (Saracci, 1977). A further problem arises in the evaluation of the marked excess mortality from laryngeal cancer. A prevalence and mortality study

Table 8 Crude and age-standardised death rates per 1000 person-years and relative risks by selected causes

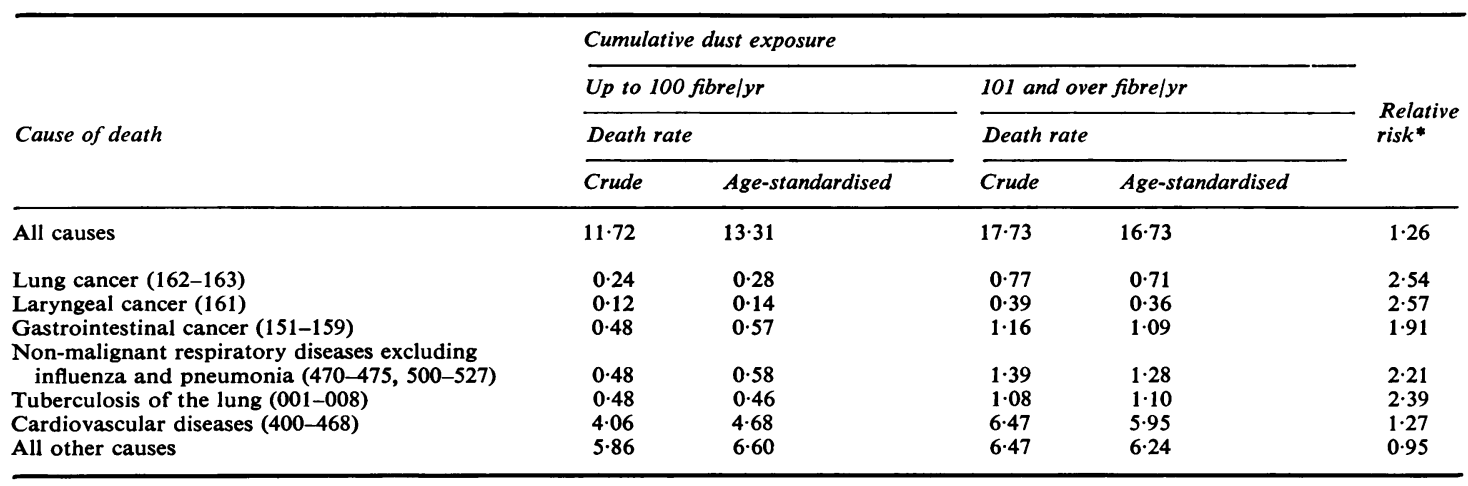

*Based on age-standardised death rates. 
was made by Terracini et al. (1974) using cancer registry data and, although the prevalence may have been overestimated, they showed that the Province of Turin, which includes the Balangero area, had one of the highest incidences of laryngeal cancer in the world in recent years. To apply national figures to the Balangero cohort would, therefore, overestimate the risk, although it has not yet been assessed whether asbestos could be an aetiological factor in the excessive rates in Piedmont. Apart from the dockyards, the greater part of the Italian asbestos industry is concentrated in the Province. Stell and MacGill (1973) and Shettigara and Morgan (1975) in hospital-based studies have both shown a positive association, but among the chrysotile miners in Quebec no excess mortality was demonstrated (McDonald and Liddell, 1979).

Internal comparison between death rates in the higher and lower exposure categories (Table 8) demonstrated a relative risk greater than two only for cancer of lung and larynx, chronic respiratory disease including asbestosis, and tuberculosis. The difference in mortality did not result from a different distribution of the times of starting employment. In fact, only 136 workers of the cohort were engaged between 1950 and $1965,65 \%$ of them reaching the high exposure level, which is about the same proportion observed in Table 7 for the cohort as a whole. The small differences between crude and agestandardised death rates demonstrate that there is no substantial difference in age distribution. It is therefore likely that the increasing mortality truly reflects the effects of higher exposure.

The cancer risk among chrysotile miners has been shown by McDonald et al. (1974) to be lower than among asbestos workers in different occupations and exposed to other types of asbestos. Jones et al. (1976), in a study of gas mask assemblers who used only crocidolite, have demonstrated a high risk of mesothelial tumours. Asbestos factory workers making textiles and other products and exposed to all three types of asbestos have a very high mortality from cancer and asbestosis (Newhouse, 1973). Selikoff $\boldsymbol{e t}$ al. (1972) have shown a considerable risk of asbestosrelated diseases in amosite workers. McDonald et al. (1974), in studies of the chrysotile miners of Canada, demonstrated a dose-response relationship between lung cancer and cumulative exposure. They emphasise that only high levels of exposure in mining and milling have an appreciable effect on mortality. In our study, with a relatively small population and only 11 certified deaths from lung cancer, it was not practical to grade the mortality from lung cancer into more than two levels of exposure.

At the Balangero mine, where exposure levels previously were high, very considerable improve- ment has taken place. Further studies are required to evaluate the effect of previous exposure, to monitor mortality from mesothelial tumours and to assess the efficacy of current control methods.

We wish to thank Professor E. Occella, Department of Mineralogy, Polytechnic of Turin, for designing and carrying out the simulation experiments; Sig. Bianchere and Ghignone for interviewing and tracing documents; Engineer Angelotti for his invaluable assistance at the mine, and Professor E. Vigliani for his help and encouragement and Professor J. C. McDonald for reading the manuscript. We would also like to thank Amiantifera, Balangero, for their support.

\section{References}

Case, R. A. M., and Lea, A. J. (1955). Mustard gas poisoning, chronic bronchitis and lung cancer. British Journal of Preventive and Social Medicine, 9, 62-72.

Enterline, P. E. (1976). Pitfalls in epidemiological research. An examination of asbestos literature. Journal of Occupational Medicine, 18, 150-156.

Ghezzi, I., Aresini, G., and Vigliani, E. C. (1972). Il rischio di asbestosi in una miniera di amianto crisotilo. La Medicina del Lavoro, 5-6, 33-56.

Jones, J. S. P., Pooley, F. D., and Smith, P. L. (1976). Factory populations exposed to crocidolite asbestos. IARC Scientific Publication No. 13, pp. 117-120. International Agency for Research on Cancer: Lyon.

Liddell, F. D. K., McDonald, J. C., and Thomas, D. C. (1977). Methods of cohort analysis. Appraisal by application to asbestos mining. Journal of the Royal Statistical Society, 144, 469-491.

McDonald, J. C. (1973). Cancer in chrysotile mines and mills. IARC Scientific Publication No. 8, pp. 189-193. International Agency for Research on Cancer: Lyon.

McDonald, J. C., Becklake, M. R., Gibbs, G. W., Macdonald, A. D., and Rossiter, C. E. (1974). The health of chrysotile asbestos mine and mill workers of Quebec. Archives of Environmental Health, 28, 61-68.

McDonald, J. C., and Liddell, F. D. K. (1979). Mortality in Canadian miners and millers exposed to chrysotile. Annals of the New York Academy of Sciences, in press.

Mantel, N., and Haenszel, W. (1959). Statistical aspects of the analysis of data from retrospective studies of diseases. Journal of the National Cancer Institute, 22, 719-748.

Newhouse, M. L. (1973). Cancer among workers in the asbestos textile industry. In Biological Effects of Asbestos, pp. 203-209. International Agency for Research on Cancer: Lyon.

Saracci, R. (1977). Asbestos and lung cancer: an analysis of the epidemiological evidence on the asbestos-smoking interaction. International Journal of Cancer, 20, 323-331.

Selikoff, I. J., Hammond, E. C., and Churg, J. (1972). Carcinogenicity of amosite asbestos. Archives of Environmental Health, 25, 183-187.

Shettigara, P. T., and Morgan, R. W. (1975). Asbestos, smoking and laryngeal carcinoma. Archives of Environmental Health, 30, 517-519.

Stell, P. M., and MacGill, T. (1973). Asbestos and laryngeal carcinoma. Lancet, 2, 416-417.

Terracini, B., Anglesio, E., Cappa, A. P. M., Coverlizza, S., 
Panno, M., and Pastore, G. (1974). Studio sull'alta incidenza dei tumori maligni della larginge nella Provincia di Torino. Tumori, 60, 143-156.
World Health Organization (1957). Manual of the International Statistical Classification of Diseases, Injuries and Causes of Death, Seventh revision. WHO: Geneva. 